\title{
PERSEPSI MASYARAKAT LOKAL TERHADAP PROGRAM PEMBANGUNAN TRANSMIGRASI DI PULAU ENGGANO KABUPATEN BENGKULU UTARA
}

\author{
Mujianto ${ }^{1)}$, Satria Putra Utama ${ }^{2)}$, Gunggung Senoaji ${ }^{3)}$ \\ ${ }^{1)}$ Biro Pemerintahan dan Kesejahteraan Rakyat Setda Provinsi Bengkulu \\ ${ }^{2)}$ Jurusan Kehutanan Fakultas Pertanian Universitas Bengkulu \\ ${ }^{3)}$ Jurusan Kehutanan akultas Pertanian Universitas Bengkulu
}

\begin{abstract}
ABSTRAK
Pembangunan kawasan transmigrasi dilakukan untuk meningkatkan kesejahteraan penduduk, menjaga keseimbangan pertumbuhan ekonomi serta keserasian budaya antar wilayah, baik secara regional maupun nasional. Pada lingkup lokal, pembangunan transmigrasi diharapkan dapat mendorong perkembangan pusat-pusat pertumbuhan ekonomi baru. Penelitian ini bertujuan untuk mengetahui persepsi masyarakat lokal terhadap program pembangunan transmigrasi di Pulau Enggano, mengetahui keinginan masyarakat lokal terhadap jenis transmigrasi yang cocok diterapkan di Pulau Enggano, mengetahui keinginan masyarakat lokal terhadap pola transmigrasi di Pulau Enggano, mengetahui keinginan masyarakat lokal terhadap komposisi penempatan transmigran di Pulau Enggano, dan mengetahui keinginan masyarakat terhadap manfaat program pembangunan transmigrasi di Pulau Enggano. Berdasarkan hasil penelitian yang telah dilakukan maka didapatkan hasil sebagai berikut untuk persepsi masyarakat lokal terhadap program pembangunan transmigrasi di Pulau Enggano termasuk kategori tinggi. 30,06 \% masyarakat memilih program transmigrasi umum. Sedangkan 34,31\% memilih pola transmigrasi umum lahan kering. Untuk komposisi penempatan transmigran di Pulau Enggano sebesar 30,36 \% memilih penempatan transmigrasi 50\% dari daerah asal (pengirim), 50\% warga local dan sebesar 17,43\% masyarakat berharap lalu lintas transportasi semakin lancar.
\end{abstract}

Kata Kunci : transmigrasi, persepsi, masyarakat lokal

\section{PENDAHULUAN}

Lambannya pembangunan di Indonesia bersumber dari kemiskinan dan keterbelakangan di daerah pedesaan karena kekurangan dalam usaha kerja dan kurangnya prasarana desa. Hal ini dapat diatasi dengan pemindahan penduduk dari pedesaan Jawa dan Bali ke daerah-daerah lain yang disebut dengan program transmigrasi. Program transmigrasi ini dapat membuat daerah-daerah baru menjadi lebih maju dan merekatkan persatuan nasional. Menurut Mursito (1982) dalam Said (1987), program transmigrasi merupakan kunci mensukseskan pembangunan pedesaan dan pembangunan bangsa. Sebab berhasilnya program transmigrasi dapat membuka peluang untuk memecahkan masalah pangan dan lapangan kerja. Said (1987) menyatakan bahwa transmigrasi diperlukan untuk memecahkan masalah kependudukan dan mendukung pengisian Wawasan Nusantara, membina persatuan dan kesatuan bangsa, serta mewujudkan dan mengembangkan budaya nasional yang dapat saling memperkaya unsurunsurnya.

Transmigrasi diharapkan akan mampu menciptakan keseimbangan penyebaran penduduk sesuai dengan daya tampung sosial, agraris dan ekologis. Daya tampung sosial adalah jumlah yang dapat 
ditampung di suatu daerah tanpa menimbulkan ketegangan-ketegangan sosial yang berarti (Heeren, 1979 dalam Limpo, 2013). Diharapkan transmigrasi di masa yang akan datang dapat didasarkan pada kebutuhan pengarahan dan persebaran penduduk ke daerah yang membutuhkan dan memenuhi kebutuhan pembangunan daerah.

Kawasan Enggano memiliki prospek untuk berkembang sebagai kawasan transmigrasi. Melalui dukungan investor, Pemerintah Kabupaten Bengkulu Utara dan stakeholder lainnya, serta sistem kelembagaan dan agribisnis yang tepat dan efektif, maka dalam jangka waktu tertentu kawasan ini dapat diproyeksikan sebagai Kawasan Kota Terpadu Mandiri. Diharapkan kedepannya dapat menjadi pendorong perkembangan wilayah/kawasan strategis di Kabupaten Bengkulu Utara secara keseluruhan.

Berdasarkan data dari Kantor Kecamatan Enggano pada tahun 2018 jumlah penduduk Pulau Enggano adalah 3.995 jiwa yang mayoritas mata pencahariannya sebagai nelayan dan petani di lahan kering. Saat ini jumlah penduduknya terus bertambah, baik yang datang secara perorangan maupun adanya program pemerintah diantaranya dengan penempatan transmigran di pulau tersebut. Pada tabel di bawah ini merupakan jumlah penduduk Pulau Enggano yang ada saat ini.

Tabel 1. Jumlah penduduk Pulau Enggano

\begin{tabular}{lccc}
\hline \multirow{2}{*}{ Desa } & \multicolumn{2}{c}{ Penduduk } \\
\cline { 2 - 4 } & & KK & Jiwa \\
\hline Kahyapu & 152 & 543 \\
Kaana & 214 & 738 \\
Malakoni & & 213 & 1055 \\
Meok & 190 & 652 \\
Apoho & 84 & 279 \\
Banjar Sari & & 257 & 728 \\
\hline \multicolumn{2}{c}{ Jumlah } & 1110 & 3995 \\
\hline
\end{tabular}

Sumber : Kantor Kecamatan Enggano Tahun 2018

Kawasan Enggano akan dapat berkembang dengan baik kalau ada sinergi antara program pemerintah dengan dukungan masyarakat dalam pembangunan ekonomi khususnya sektor pertanian. Dukungan masyarakat dalam pembangunan sangat penting karena potensi pertumbuhan ekonomi wilayah ini sangat bergantung pada sektor pertanian.

\section{Tujuan Penelitian}

Penelitian ini memiliki tujuan sebagai berikut :
1. Mengetahui persepsi masyarakat lokal terhadap program pembangunan transmigrasi di Pulau Enggano.

2. Mengetahui keinginan masyarakat lokal terhadap jenis transmigrasi yang cocok diterapkan di Pulau Enggano.

3. Mengetahui keinginan masyarakat lokal terhadap pola transmigrasi di $\mathrm{Pu}$ lau Enggano.

4. Mengetahui keinginan masyarakat lokal terhadap komposisi penempatan transmigran di Pulau Enggano.

5. Mengetahui keinginan masyarakat terhadap manfaat program pembangunan transmigrasi di Pulau Enggano. 


\section{METODE PENELITIAN}

\section{Waktu dan Tempat Penelitian}

Penelitian ini dilakukan di Pulau Enggano Kabupaten Bengkulu Utara. Ditinjau dari keadaan geografisnya Pulau Enggano merupakan salah satu kecamatan yang ada di Bengkulu Utara dengan nama Kecamatan Enggano. Pulau Enggano berbatasan langsung dengan sebelah utara berbatasan dengan Samudera Indonesia dan Provinsi Bengkulu, di sebelah selatan berbatasan dengan Samudera Indonesia, di sebelah timur berbatasan dengan Samudera Indonesia dan di sebelah barat berbatasan dengan Samudera Indonesia dan Pulau Sumatera. Kawasan Enggano dari Kota Bengkulu dapat dicapai dengan beberapa moda transportasi yaitu kapal ferry, kapal perintis maupun pesawat udara.

Penelitian ini dilakukan selama 2 (dua) bulan dan dimulai pada pertengahan bulan April sampai dengan bulan Mei 2018. Lokasi penelitian dilakukan di Pulau Enggano yang meliputi Desa Kahyapu, Desa Kaana, Desa Malakoni dan Desa Banjarsari Kecamatan Enggano Kabupaten Bengkulu Utara.

\section{Jenis dan Sumber Data}

Kegiatan yang dilakukan dalam penelitian ini meliputi pengambilan data primer dan data sekunder.

\section{Data Primer}

Data primer diperoleh dari pengamatan (observasi) di lapangan, wawancara (interview), dokumentasi dan penyebaran kuesioner. Pengambilan responden dilakukan secara purposive sampling yaitu teknik penentuan sampel dengan pertimbangan tertentu. Jumlah responden sebanyak $10 \%$ dari jumlah $\mathrm{KK}$ masyarakat lokal yang tinggal di Pulau Enggano Kecamatan Enggano Kabupaten Bengkulu Utara. Seperti diketahui jumlah KK di Kecamatan Enggano adalah sebanyak 1.110 KK, dengan jumlah penduduk transmigrasi sebanyak $316 \mathrm{KK}$, sehingga jumlah masyarakat lokal adalah sebanyak 794 KK. Berdasarkan data tersebut jumlah responden yang akan diambil adalah $10 \%$ dari 794 KK. Sehingga jumlah responden yang diwawancarai sebanyak 79,4 KK yang dibulatkan menjadi $80 \mathrm{KK}$.

Kriteria masyarakat yang akan dijadikan responden secara purposive sampling adalah :

1. Kepala keluarga masyarakat lokal yang berdomisili di Pulau Enggano Kecamatan Enggano Bengkulu Utara.

2. Sehat jasmani dan rohani.

3. Bisa membaca, menulis dan berbahasa Indonesia.

Data yang dikumpulkan adalah data primer yang diperoleh secara langsung melalui observasi dan wawancara.

\section{Data Sekunder}

Data sekunder diperoleh melalui studi kepustakaan dan dokumen dari instansi yang terkait dengan penelitian.

\section{Metode Analisis Data}

Variabel yang akan diteliti dalam penelitian ini adalah persepsi dan faktorfaktor yang berhubungan dengan persepsi masyarakat lokal terhadap program pembangunan transmigrasi di Pulau Enggano Kabupaten Bengkulu Utara. Metode analisis yang digunakan dalam penelitian ini adalah metode deskriftif dengan skala linkert. Untuk melakukan penskalaan dengan metode ini, setiap responden akan diminta untuk menyatakan jawabannya terhadap pertanyaanpertanyaan di dalam kuisioner dalam lima kategori jawaban yang telah disediakan, skor jawaban responden yang akan diberikan dapat dilihat pada Tabel 2. 
Tabel 2. Nilai skoring untuk setiap kategori persepsi dan sikap

\begin{tabular}{cl}
\hline Skor & \multicolumn{1}{c}{ Kategori Persepsi } \\
\hline 1 & Sangat Tidak Setuju \\
2 & Tidak Setuju \\
3 & Ragu-Ragu \\
4 & Setuju \\
5 & Sangat Setuju \\
\hline
\end{tabular}

Seberapa besar pemahaman dan persepsi serta sikap masyarakat terhadap program transmigrasi di Pulau Enggano dapat dihitung dengan skala interval jawaban responden, yang bertujuan untuk memudahkan interpretasi hasil dengan rumus (Cooper dan Emory, 1996).

$$
\text { Skala Interval }=\frac{\mathrm{U}-\mathrm{L}}{\mathrm{k}}
$$

Tabel 3. Skor ideal tingkat pemahaman persepsi dan sikap masyarakat

\begin{tabular}{ll}
\multicolumn{1}{c}{ Range Skor } & \multicolumn{1}{c}{ Deskripsi } \\
\hline $80-143$ & Sangat Rendah \\
$144-207$ & Rendah \\
$208-271$ & Sedang \\
$272-335$ & Tinggi \\
$336-400$ & Sangat Tinggi \\
\hline
\end{tabular}

\section{HASIL DAN PEMBAHASAN}

\section{Karakteristik Responden}

Penelitian ini difokuskan terhadap persepsi masyarakat dalam memanfaatkan Program Transmigasi sebagai usaha meningkatkan ekonomi masyarakat di $\mathrm{Pu}$ lau Enggano. Penelitian ini melibatkan 80 (delapan puluh) responden masyarakat lokal. Ada beberapa elemen masyarakat yang ikut berpartisipasi dalam penelitian ini seperti perangkat desa, tokoh masyarakat
Keterangan :

$\mathrm{U} \quad=$ Skor jawaban tertinggi

$\mathrm{L}=$ Skor jawaban terendah

$\mathrm{k}=$ Jumlah kelas interval

Skala interval tersebut, selanjutnya diinterprestasikan ke dalam skor ideal tingkat pemahaman dan persepsi dan sikap masyarakat dengan kriteria pada Tabel 3. dan masyarakat lokal. Berikut ini adalah beberapa karakteristik responden yang diamati dalam penelitian ini yaitu

\section{a. Umur}

Berdasarkan hasil penelitian diketahui bahwa mayoritas responden telah berusia dewasa, yakni berusia antara 41-50 tahun sebanyak 30 (tiga puluh) orang dan usia 31-40 tahun sebanyak 20 (dua puluh) orang, dan ini dapat dilihat seperti pada Gambar 1. 


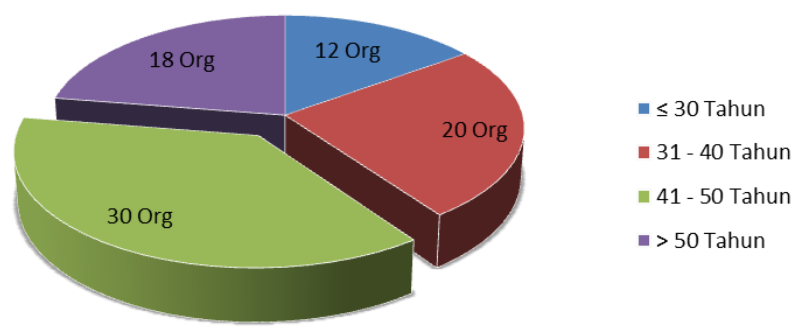

Gambar 1. Tingkat Umur Responden

Berdasarkan Gambar 1 diketahui bahwa responden yang diambil dalam penelitian ini diasumsikan dapat memahami dan memberikan persepsi objektif terhadap pertanyaan-pertanyaan yang diajukan di dalam instrumen penelitian sehingga tidak terjadi kesalahan persepsi terhadap item pertanyaan yang diajukan dalam penelitian ini.

\section{b. Tingkat Pendidikan}

Berdasarkan hasil pengamatan langsung di lapangan penyebaran respond- en pada tingkat pendidikan yang didominasi oleh responden yang memiliki tingkat pendidikan Sekolah Lanjutan Tingkat Atas (SLTA). Kondisi ini menunjukkan bahwa responden telah memiliki tingkat pendidkan yang baik. Dari hasil kuisioner diketahui dari 80 (delapan puluh) responden yang diteliti, rata-rata mereka mengenyam pendidikan Sekolah Lanjutan Tingkat Atas (SLTA), yang dapat dilihat pada Gambar 2.

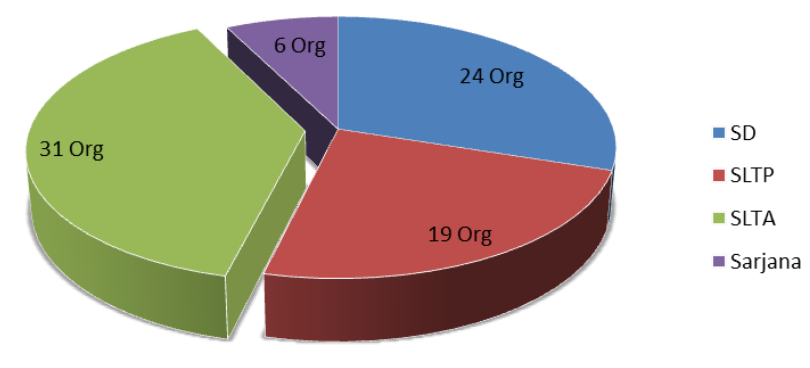

Gambar 2. Tingkat Pendidikan Responden

Gambar 2 menunjukkan bahwa responden dengan tingkat pendidikan formal Sekolah Lanjutan Tingkat Atas (SLTA) mendominasi yaitu sebanyak 31 (tiga puluh satu) responden. Sehingga jelas terlihat bahwa tingkat pendidikan responden di Pulau Enggano cenderung tinggi. Tingginya pendidikan menyebabkan masyarakat memiliki kesadaran yang cukup dalam memahami manfaat dari Program Trans- migrasi yang dilakukan di daerahnya. Semakin tinggi tingkat pendidikan maka akan lebih mudah menerima serta mengembangkan pengetahuan dan teknologi.

\section{c. Pekerjaan}

Usaha memenuhi kebutuhan seharihari, masyarakat setempat memiliki berbagai mata pencaharian. Dari sekian banyaknya mata pencaharian yang dil- 
akukan oleh masyarakat, menjadi petani merupakan mata pencaharian mayoritas penduduk sebanyak 61 (enam puluh satu) orang. Sedangkan yang lainnya berprofesi sebagai nelayan, pegawai negeri, pegawai swasta dan lain-lain, untuk lebih jelasnya dapat dilihat pada Gambar 3.

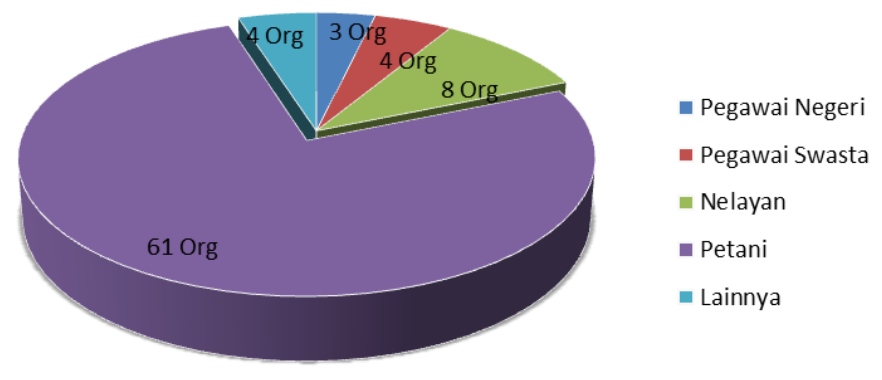

Gambar 3. Tingkat Pekerjaan Responden

Berdasarkan Gambar 3 diketahui bahwa sebagian besar masyarakat Pulau Enggano mengandalkan mata pencaharian dari sektor pertanian (sebagai petani). Hal ini menunjukkan bahwa ketergantungan masyarakat terhadap lahan sangat besar. Ini dapat dilihat juga dari sedikitnya jumlah penduduk yang bekerja dibidang non pertanian seperti sebagai nelayan, pegawai negeri, pegawai swasta dan lain-lain.

\section{d. Jangka Waktu/Lamanya Tinggal di Pulau Enggano}

Masyarakat yang telah lama tinggal mampu memahami kondisi wilayah tempat tinggalnya. Sehingga diharapkan dapat memberikan pendapat secara objektif serta memberikan kontribusi positif terhadap program tersebut. Berdasarkan hasil pengamatan yang telah dilakukan dapat dilihat pada Gambar 4.

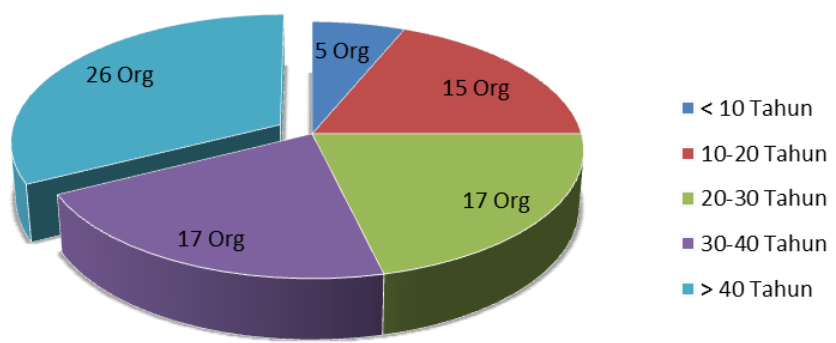

Gambar 4. Jangka Waktu Lamanya Tinggal

Gambar 4 diketahui bahwa sebagian besar responden yaitu sebanyak 26 orang merupakan masyarakat lokal yang telah tinggal di Pulau Enggano selama lebih dari 40 tahun. Ini menunjukkan bahwa sebagian besar masyarakat merupakan penduduk yang telah lama menetap di Pulau Enggano dan memahami kondisi di Pulau Enggano.

\section{e. Komposisi Suku Masyarakat Lokal}

Masyarakat lokal merupakan salah satu bagian terpenting dalam melakukan suatu kegiatan. Dukungan masyarakat lokal terhadap suatu program pemerintah sangat diharapkan, karena tanpa dukungan dari masyarakat maka kegiatan pembangunan akan sulit untuk dilakukan. Interaksi yang baik antara masyarakat lokal dan transmigran dapat menghindar konflik diantara keduanya. Komposisi suku masyarakat lokal di Pulau Enggano 
yang menjadi responden dapat dilihat pada Gambar 5.

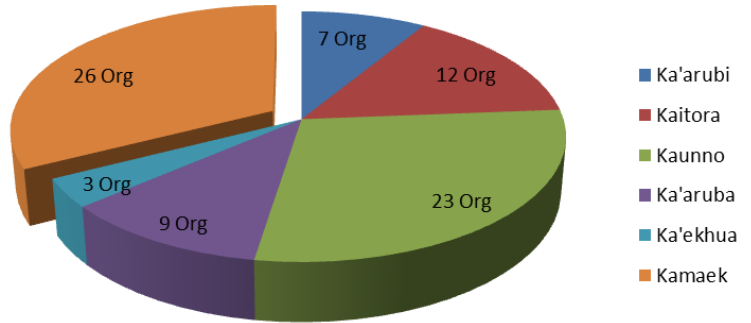

Gambar 5. Komposisi Suku Masyarakat Lokal

Berdasarkan Gambar 5 diketahui bahwa sebagian besar responden yaitu sebanyak 26 orang berasal dari Suku Kamaek, dan yang paling kecil yaitu sebanyak 3 orang berasal dari Suku Ka'ekhua.

\section{Persepsi Masyarakat Terhadap Program Pembangunan Transmigrasi}

\begin{abstract}
Berdasarkan hasil penelitian diketahui bahwa tingkat persepsi masyarakat Pulau Enggano terhadap program pembangunan transmigrasi berada pada tahap kategori tinggi sampai sangat tinggi, dan ini dapat dilihat seperti yang disajikan pada Tabel 3.
\end{abstract}

Tabel 3. Persepsi Masyarakat Terhadap Program Pembangunan Transmigrasi

\begin{tabular}{|c|c|c|c|c|c|c|c|}
\hline \multirow{2}{*}{ No } & \multirow{2}{*}{ Pernyataan } & \multicolumn{5}{|c|}{ Jawaban } & \multirow{2}{*}{ Jumlah } \\
\hline & & SS & $S$ & RR & TS & STS & \\
\hline 1 & $\begin{array}{l}\text { Transmigrasi di Pulau Enggano } \\
\text { dilakukan dengan Program } \\
\text { melibatkan masyarakat lokal }\end{array}$ & 42 & 38 & & & & 362 \\
\hline 2 & $\begin{array}{l}\text { Program transmigrasi diketahui } \\
\text { melalui media masa dan media } \\
\text { elektronik }\end{array}$ & 15 & 32 & 26 & 6 & 1 & 294 \\
\hline 3 & $\begin{array}{l}\text { Program transmigrasi diketahui } \\
\text { melalui Sosialisasi Petugas } \\
\text { Pemerintah }\end{array}$ & 32 & 44 & 3 & 1 & & 347 \\
\hline 4 & $\begin{array}{l}\text { Program transmigrasi diketahui } \\
\text { melalui pendidikan formal di } \\
\text { sekolah }\end{array}$ & 5 & 42 & 29 & 4 & & 288 \\
\hline 5 & $\begin{array}{l}\text { Program Transmigrasi di Pulau } \\
\text { Enggano merupakan salah satu } \\
\text { upaya Pemerintah untuk } \\
\text { memajukan Pulau Enggano }\end{array}$ & 56 & 23 & & 1 & & 374 \\
\hline 6 & $\begin{array}{l}\text { Penambahan penduduk melalui } \\
\text { Program Transmigrasi dapat } \\
\text { mempercepat pembangunan di } \\
\text { Pulau Enggano }\end{array}$ & 50 & 28 & 2 & & & 368 \\
\hline 7 & $\begin{array}{l}\text { Peningkatan ekonomi masyarakat } \\
\text { lokal dapat dilakukan dengan } \\
\text { program transmigrasi }\end{array}$ & 19 & 43 & 17 & 1 & & 320 \\
\hline 8 & $\begin{array}{l}\text { Program transmigrasi dapat } \\
\text { mentransfer ilmu tentang budidaya } \\
\text { pertanian dan perikanan }\end{array}$ & 14 & 34 & 28 & 4 & & 298 \\
\hline \multirow[t]{2}{*}{9} & $\begin{array}{l}\text { Program transmigrasi dapat } \\
\text { mentransfer budaya dari daerah asal } \\
\text { transmigran. }\end{array}$ & 12 & 44 & 18 & 6 & & 302 \\
\hline & \multicolumn{6}{|c|}{ Rata-Rata Persepsi } & 328.11 \\
\hline
\end{tabular}


Keterangan :

80- 143 Sangat Rendah

144-207 Rendah

208-271 Sedang

272-335 Tinggi

336-400 Sangat Tinggi

Pada Tabel 3 menunjukkan bahwa masyarakat di Pulau Enggano sudah memiliki pemahaman yang baik terhadap program pembangunan transmigrasi. Ini dapat dilihat dari nilai rata-rata persepsi masyarakat adalah 328,11 (kategori tinggi). Menurut Fuad (2003) dalam Auliyansyah, dkk (2017) persepsi masyarakat terhadap suatu kegiatan merupakan faktor penting dalam pelaksanaan kegiatan tersebut, karena tanpa adanya persepsi atau pemahaman yang baik terhadap suatu kegiatan tersebut maka pembinaan yang dilakukan tidak akan berhasil dan mengakibatkan kegiatan tersebut menjadi gagal serta tidak bermanfaat.

\section{Keinginan Masyarakat Terhadap Jenis Transmigrasi}

Hasil penelitian, maka diperoleh hasil seperti ditunjukkan pada Tabel 4.

Tabel 4. Keinginan Masyarakat Terhadap Jenis Transmigrasi

\begin{tabular}{clcc}
\hline No & \multicolumn{1}{c}{ Pernyataan } & Jumlah & \% \\
\hline 1 & $\begin{array}{l}\text { Program Transmigrasi di Pulau Enggano yang } \\
\text { tepat adalah Transmigrasi Umum (TU) }\end{array}$ & 370.06 \\
2 & $\begin{array}{l}\text { Program Transmigrasi di Pulau Enggano yang } \\
\text { tepat adalah Transmigrasi Swakarsa Mandiri } \\
(\text { TSM). }\end{array}$ & 248 & 20.15 \\
3 & $\begin{array}{l}\text { Program Transmigrasi di Pulau Enggano yang } \\
\text { tepat adalah Transbangdep }\end{array}$ & 206 & 16.73 \\
4 & $\begin{array}{l}\text { Program Transmigrasi di Pulau Enggano yang } \\
\text { tepat adalah Transmigrasi Bedol Desa. } \\
\text { Program Transmigrasi di Pulau Enggano yang } \\
\text { tepat adalah Transmigrasi Sosial (Transos) }\end{array}$ & 208 & 16.17 \\
\hline
\end{tabular}

Keinginan masyarakat terhadap jenis transmigrasi untuk transmigrasi umum memiliki skor nilai tertinggi sebesar 370 atau 30,06 \% memilih transmigrasi umum sebagai program transmigrasi yang dapat dilaksanakan di Pulau Enggano, dimana masyarakat di Pulau Enggano cenderung lebih memilih transmigrasi umum sebagai jenis transmigrasi yang dapat diterapkan di Pulau Enggano.Transmigrasi umum adalah program transmigrasi yang disponsori dan dibiayai secara keseluruhan oleh pihak pemerintah melalui Departemen Tenaga Kerja dan Transmigrasi.

\section{Keinginan Masyarakat Terhadap Pola Transmigrasi}

Tingkat keinginan masyarakat terhadap pola transmigrasi di Pulau Enggano dapat dilihat pada Tabel 5. 
Tabel 5. Keinginan Masyarakat Terhadap Pola Transmigrasi

\begin{tabular}{clcc}
\hline No & \multicolumn{1}{c}{ Pernyataan } & Jumlah & $\%$ \\
\hline 1 & $\begin{array}{l}\text { Program Transmigrasi di Pulau Enggano yang tepat adalah pola } \\
\text { Transmigrasi Nelayan }\end{array}$ & 321 & 31.47 \\
2 & $\begin{array}{l}\text { Program Transmigrasi di Pulau Enggano yang tepat adalah pola } \\
\text { Transmigrasi Umum Lahan Kering }\end{array}$ & 350 & 34.31 \\
3 & $\begin{array}{l}\text { Program Transmigrasi di Pulau Enggano yang tepat adalah pola } \\
\text { Transmigrasi Plasma Perkebunan }\end{array}$ & 349 & 34.22 \\
\hline & Jumlah & 1020 & 100 \\
\hline
\end{tabular}

Berdasarkan hasil penelitian diketahui bahwa pola transmigrasi umum lahan kering memiliki skor nilai tertinggi sebesar 350 atau sebesar 34,31\%. Tingkat keinginan masyarakat terhadap pola transmigrasi di Pulau Enggano ditunjukkan dengan memilih program transmigrasi dengan pola transmigrasi umum lahan kering. Hal ini dikarenakan rata-rata masyarakat di Pulau Enggano mengandalkan dari sektor pertanian (sebagai petani). Dan ini menunjukkan keterikatan masyarakat dengan lahan di Pulau Enggano sangat tinggi. Ketergantungan masyarakat terhadap lahan sangat nampak, ini dapat dilihat dari sedikitnya masyarakat yang bekerja di bidang non pertanian seperti pegawai negeri, pegawai swasta dan lainlain.

\section{Keinginan Masyarakat Terhadap Komposisi Penempatan Transmigran}

Tabel 6 berikut ini menyajikan tingkat keinginan masyarakat terhadap komposisi penempatan transmigran sesuai dengan item-item pertanyaan.

Tabel 6. Keinginan Masyarakat Terhadap Komposisi Penempatan Transmigran

\begin{tabular}{clcc}
\hline No & \multicolumn{1}{c}{ Pernyataan } & Jumlah & $\%$ \\
\hline 1 & $\begin{array}{l}\text { Penempatan Transmigrasi di Pulau Enggano yang tepat adalah 100 } \\
\text { \% dari daerah asal (Pengirim) }\end{array}$ & 205 & 19.27 \\
2 & $\begin{array}{l}\text { Penempatan Transmigrasi di Pulau Enggano yang tepat adalah } \\
\text { 80\% dari daerah asal (Pengirim), 20\% warga lokal }\end{array}$ & 237 & 22.27 \\
3 & $\begin{array}{l}\text { Penempatan Transmigrasi di Pulau Enggano yang tepat adalah } \\
60 \% \text { dari daerah asal (Pengirim), 40\% warga lokal } \\
\text { Penempatan Transmigrasi di Pulau Enggano yang tepat adalah } \\
\text { 50\% dari daerah asal (Pengirim), 50\% warga lokal }\end{array}$ & 299 & 28.10 \\
\hline & \multicolumn{1}{c}{ Jumlah } & 1064 & 323 \\
\hline
\end{tabular}

Berdasarkan Tabel 6 dapat dilihat bahwa keinginan masyarakat terhadap komposisi penempatan transmigran dengan skor nilai tertinggi sebesar 323 atau sebesar $30,36 \%$ yang berarti masyarakat mendukung penempatan transmigrasi di Pulau Enggano adalah $50 \%$ dari daerah asal (pengirim) dan $50 \%$ warga lokal.
Dengan komposisi tersebut, diharapkan proses pembauran antara pendatang dan penduduk lokal lebih cepat terjadi.

Keinginan $\begin{aligned} & \text { Masyarakat } \\ & \text { Manfaat Program }\end{aligned}$ Pembangunan
Transmigrasi


Keinginan masyarakat terhadap
manfaat program pembangunan

transmigrasi disajikan dalam Tabel 7.

Tabel 7. Keinginan Masyarakat Terhadap Manfaat Program Pembangunan Transmigrasi

\begin{tabular}{clcc}
\hline No & \multicolumn{1}{c}{ Pernyataan } & Jumlah & $\%$ \\
\hline 1 & $\begin{array}{l}\text { Lalu lintas transportasi di Pulau Enggano semakin lancar dengan } \\
\text { adanya program pembangunan transmigrasi }\end{array}$ & 347 & 17.43 \\
2 & $\begin{array}{l}\text { Arus komunikasi di Pulau Enggano semakin lancar dengan } \\
\text { adanya program pembangunan transmigrasi }\end{array}$ & 318 & 15.97 \\
3 & $\begin{array}{l}\text { Jalan-jalan di pulau Enggano menjadi lancar dengan adanya } \\
\text { program pembangunan transmigrasi }\end{array}$ & 311 & 15.62 \\
4 & $\begin{array}{l}\text { Program pembangunan transmigrasi membuka isolasi daerah } \\
\text { terpencil di Pulau Enggano }\end{array}$ & 338 & 16.98 \\
5 & $\begin{array}{l}\text { Usaha di Pulau Enggano semakin berkembang dengan adanya } \\
\text { program pembangunan transmigrasi }\end{array}$ & 336 & 16.88 \\
6 & $\begin{array}{l}\text { Bangunan fasilitas umum di Pulau Enggano menjadi lebih baik } \\
\text { dengan adanya program pembangunan transmigrasi }\end{array}$ & 341 & 17.13 \\
\hline & $\quad$ Jumlah & 1991 & 100 \\
\hline
\end{tabular}

Berdasarkan Tabel 7 diketahui bahwa skor nilai tertinggi sebesar 347 atau $17,43 \%$ masyarakat berharap dapat menerima manfaat dari program transmigrasi di Pulau Enggano seperti lalu lintas transportasi semakin lancar, dapat membuka isolasi daerah terpencil, usaha semakin berkembang dan bangunan fasilitas umum menjadi lebih baik. Program transmigrasi diharapkan dapat memberikan manfaat yang besar bagi kehidupannya sehari-hari, tidak hanya manfaat secara ekonomi, namun juga mendapatkan manfaat sosial. Secara ekonomi program transmigrasi dapat menjadi pusat pertumbuhan ekonomi dan lalu lintas distribusi barang jasa, ini dapat dilihat dari banyaknya masyarakat yang mulai membuka usaha di Pulau Enggano. Secara sosial dapat menjalin relasi sosial antara masyarakat lokal dan masyarakat pendatang, Program transmigrasi ini diharapkan akan dapat meningkatkan kesejahteraan masyarakat di Pulau Enggano.

\section{KESIMPULAN}

Berdasarkan hasil analisis dapat disimpulkan bahwa:

a. Persepsi masyarakat lokal terhadap program pembangunan transmigrasi di $\mathrm{Pu}-$ lau Enggano termasuk kategori tinggi.

b. Keinginan masyarakat lokal terhadap jenis transmigrasi yang cocok diterapkan di Pulau Enggano adalah sebesar $30.06 \%$ memilih program transmigrasi umum.

c. Keinginan masyarakat lokal terhadap pola transmigrasi di Pulau Enggano adalah sebesar 34,31\% memilih pola transmigrasi umum lahan kering.

d. Keinginan masyarakat lokal terhadap komposisi penempatan transmigran di Pulau Enggano adalah sebesar 30,36 \% memilih penempatan transmigrasi $50 \%$ dari daerah asal (pengirim), 50\% warga lokal.

e. Keinginan masyarakat terhadap manfaat program pembangunan transmigrasi di Pulau Enggano adalah sebesar 17,43 \% masyarakat berharap lalu lintas transportasi semakin lancar. 


\section{DAFTAR PUSTAKA}

Arifiani, Adita N., dan Mussadun. 2016. Studi Persepsi Masyarakat terhadap Tingkat Keberlanjutan Wilayah Pesisir Kecamatan Sarang. Jurnal Wilayah dan Lingkungan. Volume 4 Nomor 3, Desember 2016 : Hal. 171-186.

Auliyansyah, A., Roslinda E, dan Dirhamsyah. 2017. Persepsi Masyarakat Tentang Pembangunan Hutan Kota di UPTD Agribisnis Kelurahan Siantan Hulu Kecamatan Pontianak Utara. Jurnal Hutan Lestari. Volume 5 (3) : Hal 599609.

Limpo, S Y. 2013. Peranan Pemerintah Provinsi dalam Pengembangan Program Transmigrasi Mewujudkan Pembangunan Daerah. Buku Transmigrasi : Solusi Permasalahan Bangsa. Hal. 107114.

Masria., G, dan Ihsan M. 2015. Persepsi dan Sikap Masyarakat Lokal Terhadap Hutan di Desa Labuan Toposo Kecamatan Labuan Kabupaten Donggala. Warta Rimba. Volume 3 Nomor 2 : Hal 57-64.

Novayanti, D., Irwan S B, Rahmat S, Christine W, dan Indra G F. 2017. Analisis Faktor-Faktor yang Mempengaruhi Persepsi Masyarakat dalam Pembangunan Hutan Tanaman Rakyat pada KPH Gedong Wani. Jurnal Hutan dan Masyarakat. Vol.9 (2) : Hal 61-74.

Nugraha, A Tjachja., Sumarna H, dan Yuliana S. 2015. Model
Pengembangan

Kawasan

Transmigran, Kecamatan Waplau, Kabupaten Buru, Provinsi Maluku. Jurnal Agribisnis, Vol.9 No.1. Juni 2015. Hal. 23-36.

Peli, Y S. 2012. Hubungan Antara Persepsi, Sikap dan Kenyamanan Masyarakat Dengan Kualitas Lingkungan Sosial Di Sekitar Keberadaan Gardu Distribusi Tegangan Menengah. Makalah. Kota Kupang.

Said, E .G. 1987. Pembangunan dan Pelestarian Lingkungan Hidup. PT Media Sarana Press. Jakarta.

Santoso, E B., Safyan Z, dan Ahmad Y. 2014. Persepsi Masyarakat Desa Sabung Terhadap Pembangunan Kebun Raya Kabupaten Sambas. Fakultas Kehutanan Universitas Tanjungpura. Hal. 307-316.

Sujali, D R N., dan Bakti S. 2009. Persepsi dan Peran Serta Masyarakat Lokal Dalam Pengelolaan TNGM. Majalah Geografi Indonesia. Vol. 23 No. 2 September 2009 : Hal : 90-108.

Suryaningsih, W H., Hartuti P, dan Muniffatul I. 2012. Persepsi Masyarakat Dalam Pelestarian Hutan Rakyat di Desa Karangrejo Kecamatan Loano Kabupaten Purworejo. Prosiding Seminar Nasional Pengelolaan Sumberdaya Alam dan Lingkungan. Semarang 11 September 2012 : Hal. 93-97.

Suyatna, H. 2013. Dimensi Sosial Dalam Transmigrasi. Buku Transmigrasi : Solusi Permasalahan Bangsa. Hal. 193-196. 